\title{
Study on Horizontal Evaporator Tube with Different Outer Surface Roughness under Different Feeder Water Load
}

\author{
[ Alias Mohd Noor*, Lim Chih Hoo, Srithar Rajoo, Muhammad Hanafi Md Sah, Sheikh Hussain Shaikh Salleh ]
}

\begin{abstract}
Desalination plant in marine transportation consumes large amount of fresh water for a single trip. The plant is also widely used in regions where very low rainfall but near to the sea. The most important component of a desalination plant is the evaporator. An effective and efficient evaporator will enhance the collection of condensate water which can reduce the occupied space of the plant especially for marine transportation. In this study a horizontal aluminum evaporator with varying outer roughness was used under different feeder water load. The performance of each evaporator was evaluated based on the collected amount of condensate water. In parallel with the experimental works, correlation of variables were derived based on the film wise condensation Nusselt's equation, heat transfer equation and falling film equation. The mathematical correlation which was non-linear equation was solved using Maple software and the theoretical results were then compared to the experimental results. Numerical results showed that the mass flow rate of the condensate increases as the feeder water load increases. The evaporator tube with higher outer surface roughness gave higher performance, compared to the one with lower outer surface roughness. Furthermore, the improved mathematical equation shows higher accuracy compared to the previous used equation. Based on the results, the evaporator tube outer surface roughness plays a role to affect the evaporator tube performance.
\end{abstract}

Keywords - desalination, evaporator, heat transfer, condensation

Alias Mohd Noor $*$ (corresponding author)

Universiti Teknologi Malaysia

Malaysia

Lim Chih Hoo

Universiti Teknologi Malaysia

Srithar Rajoo

Universiti Teknologi Malaysia

Muhammad Hanafi Md Sah

Universiti Teknologi Malaysia

Sheikh Hussain Shaikh Salleh

Universiti Teknologi Malaysia

\section{Introduction}

In a desalination plant, evaporators are the most important part due to condensation that is taking place. Condensation will occur when the vapour temperature is reduced below its saturation temperature as mentioned by Cengel (2006). According to Noor (1980), a process similar to condensation in pipe occurs inside an evaporator when the vapour comes into contact with the surface where the temperature is lower than its saturation temperature. During this process, the heat energy from vapour inside the evaporator is transferred to the seawater feed via its wall as shown in Figure 1.

Theoretically, higher the thermal conductivity of the evaporator, better the heat transfer from the vapour which will improve condensation. Hence, an experimental study of the thermal conductivity effect on the desalination plant performance will be conducted. This will determine the relationship between the thermal conductivity of the evaporator to the vapour condensation rate, providing a good reference in choosing the most cost effective material for the evaporators.

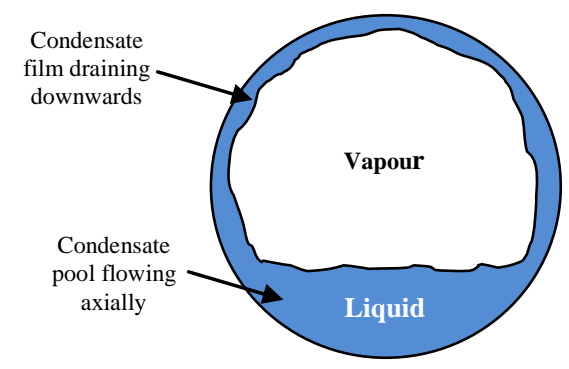

Figure 1. Condensation inside evaporator tube. (Wolverine Tube Inc 2006)

Current desalination technology can be divided into two main categories based on the underlying mechanism for removing unwanted substances in the draw water. These are the membrane process and the thermal process. The membrane process technique is where pressure is applied to push the water molecules across the semipermeable membrane while the substances are left together with the concentrated draw water. For the thermal process technique, the draw water is heated inside the boiler to produce steam and then transferred to the single or multiple evaporating chambers for the 
condensation process to take place. The fresh water is collected after condensation and stored back into the tank for daily use.

\section{Theoretical Analysis}

In the thermal process, performance ratio is used to measure its efficiency. Performance ratio represents the measure of pounds of distillate produced under per pound of motive steam applied to the process. With the innovation in multi-effect distillation plant which is using vertical arrangement of the evaporators, the performance ratio manages to reach 24 pounds of desalted water per pound of steam.

\section{A. Heat Flux Effect}

Based on a previous study by Ribatski and Jacobi (2005), heat flux does not affect the heat transfer coefficient on the evaporation side (outside the tube) when the surface is completely wet, as this will restrict any convective condition. However, under a boiling dominated condition, the heat transfer coefficient will increase due to the increasing heat flux. This is because at a boiling dominated condition, the increasing heat flux will increase the bubbles nucleation site density as well as the boiling area along the evaporator tube. The formation of the bubbles absorbs a great amount of latent heat from the tube; hence the enhanced heat transfers on the evaporation side (Wang \& Catton 2001).

\section{B. Feeder Load Effect}

Previous results as in Figure 2 showed that increasing the feeder load will affect the heat transfer coefficient on the evaporation side, which in turn will increase the total heat transfer coefficient (Xu et al. 2004a; Yang \& Shen 2008; Ribatski \& Jacobi 2005). This behavior was due to the increased flow velocity which aggravated the fluctuation of the falling film outside the tube. A higher falling film fluctuation enhanced the convective heat transfer.

Noor (1980) used Eq. (1) to calculate the condensate flow rate under different feeder loads

$$
\begin{gathered}
\text { R.H.S. } \dot{m}_{s}+J \mathrm{~m}_{s}^{\frac{4}{3}}-G=0 \\
\text { where, } G=\frac{C \pi d L}{E}\left(T_{s}-2 \beta T_{i f}\right) \\
\text { and } \quad J=\frac{C}{A}
\end{gathered}
$$

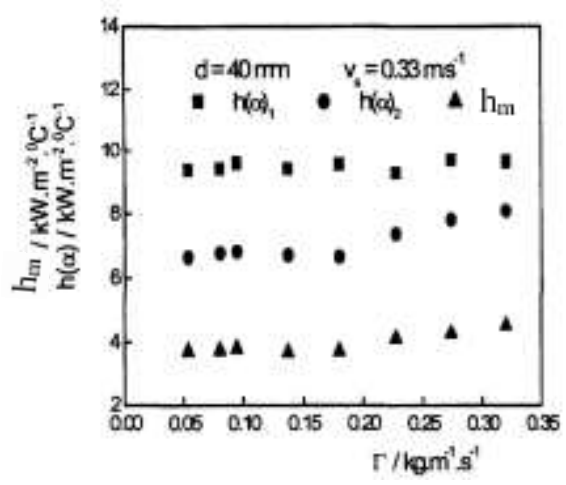

Figure 2. Effect of Feeder load, $d$ on condensation side heat transfer coefficient, $\mathrm{h}(\mathrm{a})_{1}$, evaporation side heat transfer, $\mathrm{h}(\mathrm{a})_{2}$ and total heat transfer coefficient, $\mathrm{h}_{\mathrm{m}}$. (Xu et al. 2004a)

For the boiling dominated condition, the heat transfer coefficient on the evaporation side was independent of the feeder load due to the predominance of the boiling effect. The bubbles nucleation aggravated the liquid film fluctuation and turned the flow into turbulent flow (Ribatski \& Jacobi 2005). Besides that, a larger amount of heat was absorbed during the liquid-vapour phase change as compared to the convective heat transfer of the film (Wang \& Catton 2001).

\section{Evaporation Boiling Point Effect}

When the evaporation boiling point increases, the heat transfer coefficients for condensation and evaporation as well as the total heat transfer increase greatly. This is because with a higher boiling point, both liquid films (on the outside and inside of the tube) mucosity decreased while the flow velocity increased. The liquid film became thinner which helped to improve heat transfer (Xu et al. 2004a, 2004b; Ribatski \& Jacobi 2005).

On the other hand, Leroy and Sernas (1974) had conducted an investigation on the heat transfer for 1" and 2" diameter smooth 90/10 copper-nickel tubes at saturation temperature ranging from $321.89 \mathrm{~K}(11.65 \mathrm{kPa})$ to $400 \mathrm{~K}(244.28 \mathrm{kPa})$. The investigation showed that the heat transfer on evaporation side (on the outside of the tube) increased slightly as the saturation temperature increased. The nucleate boiling within the film was also observed at all levels of heat flux at low saturation temperature with very little boiling occurring at the saturation condition above atmospheric pressure (101.325 $\mathrm{kPa})$.

\section{Piping Diameter Effect}

In a convection dominated condition, the tube diameter affects the heat transfer on the evaporation side due to the change of thermal boundary layer and the flow of the falling film (Xu et al. 2004a; Ribatski \& Jacobi 2005). Xu et al. (2004a) investigation as shown in Figure 3 explained that as the diameter of the piping decreased the heat transfer 
coefficient on the evaporation side increased. This is because as the piping diameter decreased, the fluctuations of the film on the outside of the tube increased, which in turn will help to increase the convection heat transfer on the outside of the tube. However, Figure 3 showed that the piping diameter did not greatly affect the surface heat transfer on the condensation side.

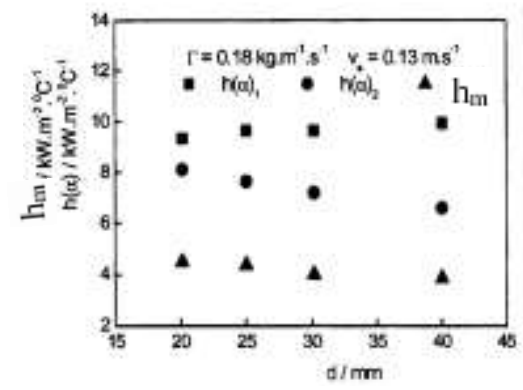

Figure 3. Effect of tube diameter, $d$ on condensation side heat transfer coefficient, $\mathrm{h}(\mathrm{a})_{1}$, evaporation side heat transfer, $\mathrm{h}(\mathrm{a})_{2}$ and total heat transfer coefficient, $\mathrm{h}_{\mathrm{m}}$. (Xu et al. 2004a)

\section{E. Steam Flow Velocity Effect}

Figure 4 shows the effect of steam flow velocity on the condensation side, evaporation side heat transfer and total heat transfer coefficient. The results show that the condensation side heat transfer increased slightly as steam flow velocity increased. However, the evaporation side and total heat transfer coefficient are almost constant. Xu et al. (2004a, 2004b) stated that the increased in steam flow velocity causes the thickness of the condensation liquid film to decrease; hence the increased in the surface heat transfer coefficient on the condensation side. Despite this, the total heat transfer coefficient only increased slightly as the surface heat transfer coefficient on the evaporation side remained constant.

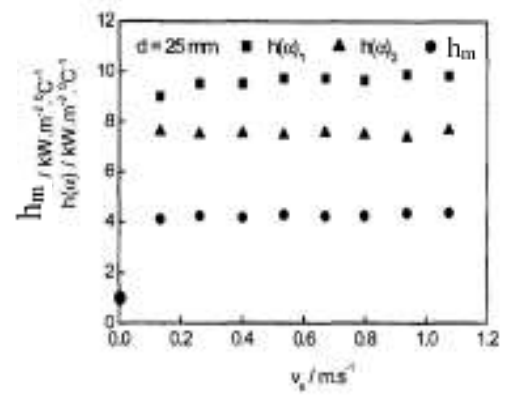

Figure 4. Effect of steam flow velocity, $\mathrm{v}_{\mathrm{s}}$ on condensation side heat transfer coefficient, $\mathrm{h}(\mathrm{a})_{1}$, evaporation side heat transfer, $\mathrm{h}(\mathrm{a})_{2}$ and total heat transfer coefficient, $\mathrm{h}_{\mathrm{m}}$. (Xu et al. 2004a)

\section{F. Existence of non-condensing gases}

According to Figure 5, the slight existence of noncondensing gases greatly decreases the heat transfer on the evaporation side. This could be due to the elimination of the vacuum point for the liquid evaporation by the noncondensing gases. As a result, the liquid was unable to reach the saturation temperature (Yang \& Shen 2008).

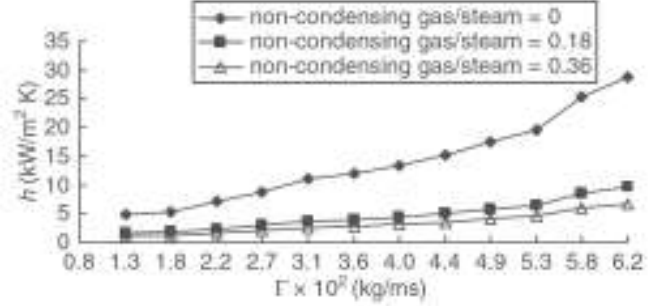

Figure 5. Effect of non-condensing gas on heat transfer coefficient for different feeder load (Yang \& Shen 2008)

\section{G. Height of the feeder}

Yang and Shen (2008) conducted a study on Al-brass evaporator with outer diameter of $14 \mathrm{~mm}$, inner diameter of $12 \mathrm{~mm}$. The feeder was a copper tube with 21 feed nozzles of 2 $\mathrm{mm}$ diameter. Yang and Shen (2008) stated that the increase in the feeder height increases the heat transfer on the evaporation side due to the increasing fluid velocity. Their results are shown in Figure 6. However if the distance of the feeder is too high which achieved $13 \mathrm{~mm}$ in Yang and Shen study, reverse effects will occur as many dry spots may exist on the tube surface.

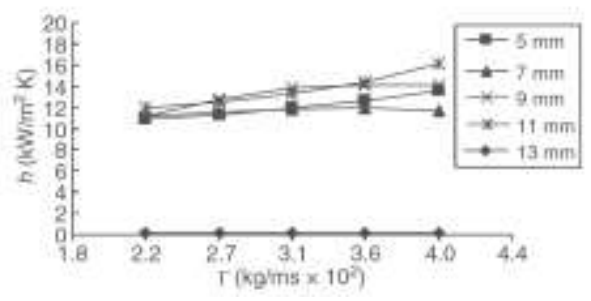

Figure 6. Effect of height of feeder to heat transfer coefficient on different feeder load (Yang \& Shen 2008)

\section{H. Condensation}

Condensation occurs when the vapour contact a solid surface of reduced temperature but below the saturation temperature. However, condensation also occurs on the free surface of liquid or gas in the condition where the temperature of the liquid or the gas is below the vapour saturation temperature. There are two kinds of condensation process, one being film condensation and the other drop wise condensation.

In normal practice, the condensate tends to wet the surface and forms a liquid film on the surface; the process is called film condensation. Under the effect of gravity, the film will slide down along the surface and form a thicker film. The thickness of the film increases as more vapour condenses until the whole solid surface is covered with a "liquid wall". This "liquid wall" produces resistance for the heat of vaporization to be transferred through the solid surface and be released to the medium on the other side (Cengel, 2006). Figure 7 shows the process of film condensation. 
Proc. of the Intl. Conf. on Advances in Civil, Structural and Mechanical Engineering - ACSM 2015. Copyright (C) Institute of Research Engineers and Doctors, USA .All rights reserved.

ISBN: 978-1-63248-039-2 doi: 10.15224/ 978-1-63248-039-2-17

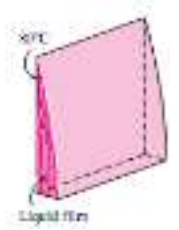

Figure 7. Film Condensations. (Cengel, 2006)

If the condensed vapour forms plenty of droplets covering the solid surface as shown in Figure 8, the process is called drop wise condensation. In drop wise condensation, small droplets on the condensing surface continue to coalesce into large droplets and slide down when they reach a certain size. While the droplets slide down along the surface, they clear the surface and expose it to vapours. Hence, there is no liquid film between the vapour and the solid surface to resist the heat transfer. As a result, the overall heat transfer can be approximately 10 times higher than the film condensation (Cengel, 2006).

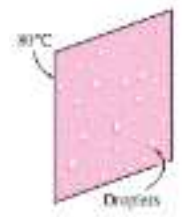

Figure 8. Drop wise Condensations. (Cengel, 2006)

\section{Modelling \& Simulation}

An equation from a previous study conducted by Noor (1980) is modified in this study and its derivations are shown hereafter. Performance of the desalination process depends on the effectiveness of heat transfer from the steam inside the tube to the feeder water through the evaporator tube wall. Hence, the three main heat transfer coefficients are included in this theoretical analysis, which are the heat transfer coefficient of condensation inside the horizontal tubes, heat transfer coefficient of the evaporator tube wall and the heat transfer coefficient of the falling film.

\section{A. Heat Transfer Coefficient of Condensation inside the Horizontal Tubes}

According to Hoyt et al. (2008), for condensation inside the horizontal tubes with Reynolds number less than 2100, the flow is laminar flow as given in Eq. (2).

$$
\begin{array}{r}
\mathrm{h}_{\mathrm{s}}=0.76 \mathrm{k}_{\mathrm{s}}\left[\frac{\rho_{\mathrm{g}}^{2} \mathrm{~g}}{\mu_{\mathrm{s}} \Gamma_{\mathrm{s}}}\right]^{\frac{1}{3}} \\
\text { where } \Gamma_{\mathrm{s}}=\dot{\mathrm{m}}_{\mathrm{s}} / 2 \mathrm{~L}
\end{array}
$$

Hoyt et al. (2008) also states that liquid properties should be used in the equation for the calculations instead of vapor properties because the study is mainly to identify the heat transfer coefficient of the condensate.

\section{B. Heat Transfer Coefficient of the Evaporator Tube Wall}

The heat transfer coefficient of the evaporator tube wall is affected by its material thermal conductivity, $\mathrm{k}_{\mathrm{w}}$ and its thickness, $\delta_{w}$ (Hoyt et al. 2008). Hence the heat transfer coefficient equation is shown in Eq. (3).

$$
\mathrm{h}_{\mathrm{w}}=\mathrm{k}_{\mathrm{w}} / \delta_{\mathrm{w}}
$$

\section{Heat Transfer Coefficient of the Falling Film}

When the feeder water is distributed uniformly around the outer surface of the horizontal evaporator tube, it flows in layer form around the tube and falls off from the bottom. According to Hoyt et al. (2008), such mechanism is called gravity flow of liquid layers of falling films. Perry also stated that the Reynolds number for the falling film which applies to the outer surface of the horizontal tube will rarely exceed 2100. Hence, the heat transfer coefficient $h_{f}$ for falling films on the outer surface of the horizontal tube is given in Eq. (4).

$$
h_{\mathrm{f}}=0.5\left(\frac{\mathrm{k}^{2} \mathrm{p}^{4 / a} \mathrm{c}_{\mathrm{p}} \mathrm{g}^{2 / a}}{\frac{\pi \mathrm{d}_{\mathrm{o}} \mu_{\mathrm{f}}^{1 / a}}{2}}\right)^{1 / \mathrm{a}}\left(\frac{\mu_{\mathrm{f}}}{\mu_{\mathrm{w}}}\right)^{1 / 4}\left(\frac{4 \Gamma_{\mathrm{f}}}{\mu_{\mathrm{f}}}\right)^{1 / 9}
$$

\section{The Analysis of the Overall Thermal Resistance of Solid and Fluid in Series}

Referring to Figure 9 the vapour condenses on the cooler wall of the tube. The condensate that is collected in the pipe flows off due to gravity.

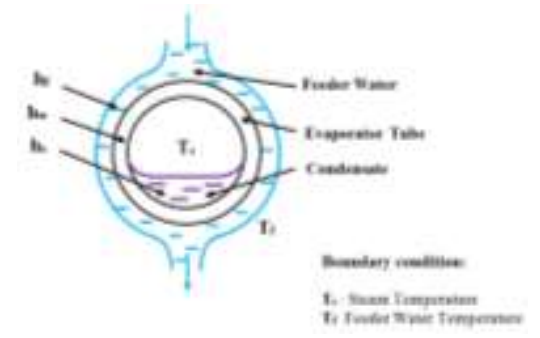

Figure 9. Condensation inside evaporator tube.

Hence, the equation for the total heat resistant given as Eq. (5).

$$
\frac{1}{\mathrm{~h}_{\mathrm{m}}}=\frac{1}{\mathrm{~h}_{\mathrm{s}}}+\frac{1}{\mathrm{~h}_{\mathrm{w}}}+\frac{1}{\mathrm{~h}_{\mathrm{f}}}
$$

where $h_{m}$ represents the overall heat transfer coefficient. The equation can then be expanded by substituting Eq. (2), 


$$
\begin{aligned}
& \mathrm{h}_{s}=0.76 \mathrm{k}_{s}\left[\frac{\rho_{s}^{2} \mathrm{~g} 2 \mathrm{~L}_{s}}{\mu_{s}}\right]^{\frac{1}{2}}\left[\frac{1}{\mathrm{~m}_{s}}\right]^{\frac{1}{a}} \\
& \text { let } A=0.76\left[\frac{\rho_{s}^{2} g}{\mu_{s}} 2 L\right]^{\frac{1}{2}}=\text { constant } \\
& \therefore \mathrm{h}_{\mathrm{s}}=\mathrm{A}\left[\frac{1}{\mathrm{~m}_{\mathrm{s}}}\right]^{\frac{1}{\mathrm{a}}}
\end{aligned}
$$

Eq. (3) and Eq. (4),

$$
\begin{gathered}
\mathrm{h}_{\mathrm{w}}=\mathrm{k}_{\mathrm{w}} / \delta_{\mathrm{w}}=\mathrm{B}=\text { constant } \\
\mathrm{h}_{\mathrm{f}}=0.5\left(\frac{\mathrm{k}_{\mathrm{f}}^{2} \mathrm{P}_{\mathrm{f}}^{\frac{4}{a}} \mathrm{c}_{\mathrm{p}} \mathrm{g}^{\frac{2}{a}}}{\frac{\pi \mathrm{d}_{0} \mu_{\mathrm{f}}^{1 / a}}{2}}\right)^{1 / a}\left(\frac{\mu_{\mathrm{f}}}{\mu_{\mathrm{w}}}\right)^{1 / 4}\left(\frac{4 \mathrm{\Gamma}_{\mathrm{f}}}{\mu_{\mathrm{f}}}\right)^{1 / 9} \\
\text { and let } \mathrm{C}=0.5\left(\frac{\mathrm{k}_{\mathrm{f}}^{2} \mathrm{P}_{\mathrm{f}}^{\frac{4}{a}} \mathrm{c}_{\mathrm{p}} \mathrm{g}^{\frac{2}{a}}}{\frac{\pi \mathrm{d}_{0} \mu_{\mathrm{f}}^{1 / a}}{2}}\right)^{1 / \mathrm{L}}\left(\frac{\mu_{\mathrm{f}}}{\mu_{\mathrm{w}}}\right)^{1 / 4}\left(\frac{4}{2 \mathrm{~L} \mu_{\mathrm{f}}}\right)^{1 / 9} \\
\mathrm{~m} \mathrm{~h}_{\mathrm{f}}=\mathrm{Cm}_{\mathrm{f}}^{\frac{1}{9}}
\end{gathered}
$$

into Eq. (5) to become Eq. (6).

$$
\frac{1}{\mathrm{~h}_{\mathrm{m}}}=\frac{\dot{\mathrm{m}}_{\mathrm{s}}^{\frac{1}{2}}}{\mathrm{~A}}-\frac{1}{\mathrm{~B}}+\frac{1}{\mathrm{Cm}_{\mathrm{f}}^{\frac{1}{9}}}
$$

Hence, the heat transfer coefficient can be obtained by rearranging Eq. (6) to become Eq. (7).

$$
\left.\mathrm{h}_{\mathrm{m}}=\frac{A B C \mathrm{~m}_{\mathrm{f}}^{\frac{1}{9}}}{\mathrm{AB}+\mathrm{Cm}_{\mathrm{f}}^{\frac{1}{9}}\left(A+\mathrm{Bm}_{\mathrm{s}}^{\frac{1}{2}}\right)}\right)
$$

By using the heat balance equation, the rate of heat condensate, $\dot{Q}_{\text {cond }}$ is equal to the rate of heat transfer through the falling water and the rate of heat transfer through the overall evaporator tube system. Hence it becomes Eq. (8).

$$
\begin{aligned}
\mathrm{Q}_{\text {cond }}=\mathrm{m}_{\mathrm{s}} & \left\{\mathrm{H}_{\mathrm{fg}}+\mathrm{C}_{\mathrm{pg}}\left(\mathrm{T}_{\mathrm{s}}-\mathrm{T}_{\text {cond }}\right)\right\} \\
& =\dot{\mathrm{m}}_{\mathrm{f}} \mathrm{C}_{\mathrm{pf}}\left(\mathrm{T}_{\mathrm{of}}-\mathrm{T}_{\mathrm{if}}\right) \\
& =\mathrm{h}_{\mathrm{m}}\left(\mathrm{T}_{\mathrm{s}}-\mathrm{T}_{\mathrm{f}}\right) \pi \mathrm{d} \mathrm{L}
\end{aligned}
$$

Solving Eq. (8) will give Eq. (9).

$$
\begin{gathered}
\qquad \dot{m}_{s}=h_{m}\left(T_{s}-T_{f}\right) \pi d L \\
\text { where } \mathrm{E}=\mathrm{H}_{\mathrm{fg}}+\mathrm{C}_{\mathrm{pl}}\left(\mathrm{T}_{\mathrm{s}}-\mathrm{T}_{\text {cond }}\right)
\end{gathered}
$$

Substituting Eq. (7) into Eq. (9) and solving the equation will result in Eq. (10).

$$
\left(\frac{1}{\dot{m}_{\mathrm{f}}^{\frac{1}{9}}}+\frac{\mathrm{C}}{\mathrm{B}}\right) \dot{\mathrm{m}}_{s}+\frac{\mathrm{C}}{\mathrm{A}} \dot{\mathrm{m}}_{s}^{\frac{4}{3}}-\frac{\mathrm{C} \pi \mathrm{dL}}{\mathrm{E}}\left(\mathrm{T}_{s}-\mathrm{T}_{\mathrm{f}}\right)=0
$$

$$
\begin{aligned}
& \text { let R.H.S. }=\frac{1}{\mathrm{~m}_{\mathrm{f}}^{\frac{1}{9}}}+\frac{\mathrm{C}}{\mathrm{B}} \\
& \text { and } \mathrm{G}=\frac{\mathrm{C} \pi \mathrm{dL}}{\mathrm{E}}\left(\mathrm{T}_{\mathrm{s}}-\mathrm{T}_{\mathrm{f}}\right) \\
& \text { also } \mathrm{J}=\frac{\mathrm{C}}{\mathrm{A}}
\end{aligned}
$$

Thus, the final form is Eq. (11) as shown below,

$$
\text { R. H.S. } \dot{m}_{s}+J^{\frac{4}{2}}-G=0
$$

By solving the final equation using Maple software, the rate of mass condensate can be defined. The equation was solved under several assumptions:

- There is no mass and heat loss in the whole desalination system during the testing and the thickness of the evaporator tube was relatively small, hence the inner surface area of the tube was assumed to be equal to the outer surface area of the tube. The outer surface area was used in the calculation.

- The temperature of the steam and feeder water was assumed to be constant during the testing.

\section{Iv. Experimental Work}

Experimental results were analyzed and compared to the theoretical values as to investigate the evaporator performance with different outer surface roughness and feeder load. The overall investigation progress is shown in Figure 10.

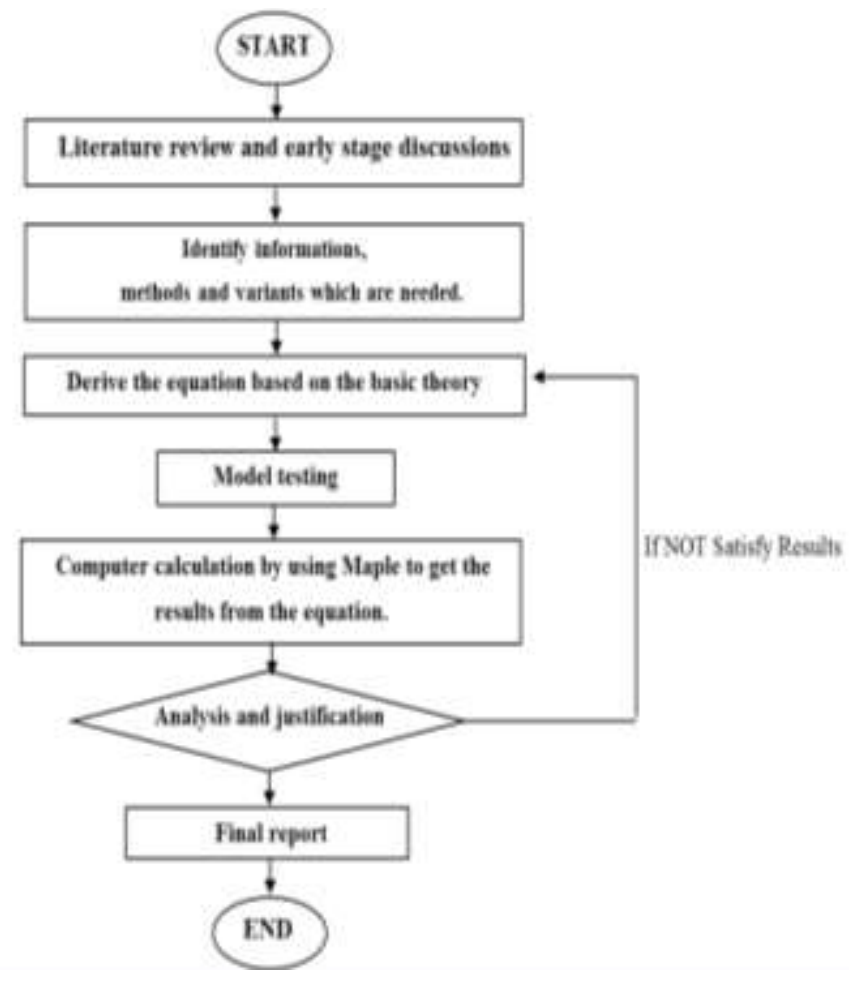

Figure 10. Flow Chart for the Investigation progress. 


\section{A. Model Testing}

The test rig is shown in Figure 11. Steam condenses inside the evaporator tube while the falling films fall on the tube.

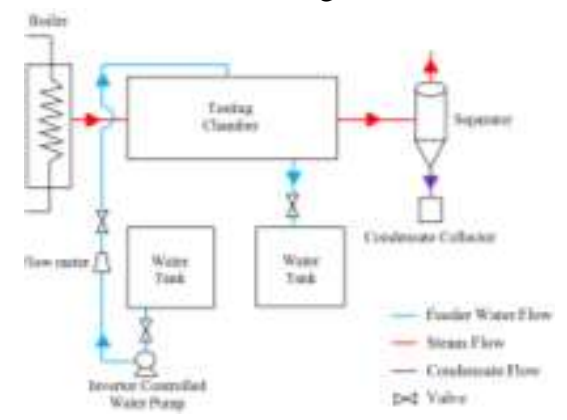

Figure 11. Schematic Diagram of Testing Rig

The feeder water from the water tank is pumped into the testing chamber to cool down the evaporator. Water that is heated by the evaporator is ejected into the second water tank. The feeder load can be adjusted to several different flow rates by using the valve and the invertor controlled pump. Five Type- $\mathrm{K}$ thermocouples are placed in the testing rig which is shown in Figure 12 for,

$\begin{array}{llll}\text { - } & \mathrm{T}_{1} & = & \text { Inlet feeder water temperature, } \mathrm{T}_{\mathrm{if}} \\ \text { - } & \mathrm{T}_{2} & = & \text { Steam temperature (in), } \mathrm{T}_{\mathrm{si}} / \mathrm{T}_{\mathrm{s}} \\ \text { - } \quad \mathrm{T}_{3} & = & \text { Steam temperature (out), } \mathrm{T}_{\mathrm{so}} \\ \text { - } \quad \mathrm{T}_{4} & = & \text { Condensate temperature, } \mathrm{T}_{\text {cond }} \\ \text { - } \quad \mathrm{T}_{5} & = & \text { Outlet feeder water temperature, } \mathrm{T}_{\text {of }}\end{array}$

All the temperatures were used in the theoretical equation to calculate the theoretical condensate flow rate results.

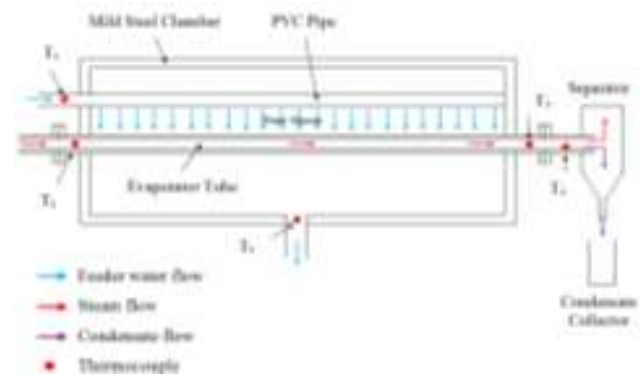

Figure 12. Schematic Diagram inside the Testing Chamber.

The experiment was run under constant steam pressure $(791.7 \mathrm{kPa})$, constant steam temperature $\left(100^{\circ} \mathrm{C}\right)$ and constant feeder water temperature $\left(29^{\circ} \mathrm{C}\right)$ in order to minimize any unnecessary effects on the testing results.

\section{B. Manipulation Factors}

Two major factors are considered for the study on the evaporator tube performance, which are the feeder water load and the evaporator tube outer surface roughness.
The feeder water load was set for 16 LPM, 20 LPM, 24 LPM, 28 LPM and 32 LPM. The range of parameters used in this study is higher compared to the work done by $\mathrm{Xu}$ et al. (2004b) because a lower feeder water load will create a large area of dry spot on the evaporator tube surface and this will affect the measurement accuracy.

Two aluminium tubes with $600 \mathrm{~mm}$ length were selected. The tubes were grinded with different grades of sandpaper to obtain different surface roughness. Tubes with rough surface were grinded with sandpaper grade 60 . For tubes with smooth surface, sandpaper grade 240 was first used, followed by grade 1000 and finally, for finishing, sandpaper grade 2000 was used. The testing area for each tube is $500 \mathrm{~mm}$ length. For both types of evaporator tube, the grinding direction was perpendicular to the axial of the tube as shown in Figure 13.

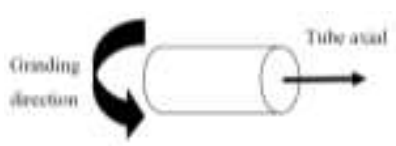

Figure 13. Grinding Direction

Surface roughness for both the tubes was studied using stylus based surface measurement machine. For each tube, five points were randomly selected for surface roughness measurements based on the distance shown in Figure 14. During the measuring process, two points were selected randomly at $8 \mathrm{~mm}$ distance from both ends of the evaporator tube which is marked as P1 and P4 points. The next measurements are P2 and P5 which were randomly selected at $20 \mathrm{~mm}$ distance from both ends of the tube. Finally, the point P3 was selected to be at the centre of the tube.

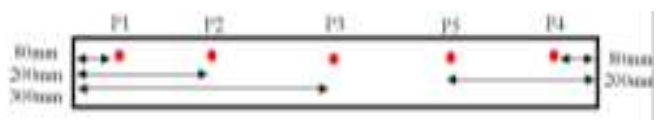

Figure 14. Surface Roughness Point Measurement of Evaporator Tube

When measuring the surface roughness at each point, the stylus touched on the tube surface and moved along a $4 \mathrm{~mm}$ track to collect five measuring profiles along the track. All the data were then transferred to the computer for integration. The average surface roughness $(\mathrm{Ra})$ on each specific point was calculated.

\section{Apparatus}

The equipment used in this study were boiler, evaporator casing, water tank, inverter controlled centrifugal water pump, flowmeter, condensate collector and evaporator tube. All details are explained below.

- Boiler 
The boiler shown in Figure 15 was used to supply steam to the evaporator during the testing. The boiler is Clayton steam generator EO-20-3, a light oil type steam generator with maximum load of $196 \mathrm{~kW}$, which is equivalent to maximum output of $313 \mathrm{~kg}$ per hour saturated steam at pressure up to 8 bar.

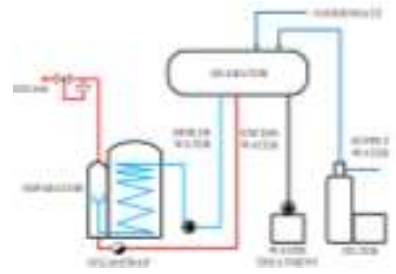

Figure 15. The Schematic Diagram of Clayton Steam Boiler EO-20-3 System.

Based on Clayton (2009), the supply water that passes through the filter that is stored inside the deaerator is mixed with the condensate, excess water and water treatment substances to become boiler water. Then the boiler water is pumped through the combustion chamber where it is gradually heated to become steam-water mixture.

The steam-water mixture is then brought into the separator. Inside the separator, the steam is separated from excess water by centrifuge and flows to the testing rig. The excess water is collected at the bottom of the separator and returns to the deaerator via a steamtrap. This prevents the excess water from rising above the separator and taken along with the steam to the testing rig which will affect measurement. The tests were carried out around 8 bar pressure and temperature of $100^{\circ} \mathrm{C}$.

- Feeder tube

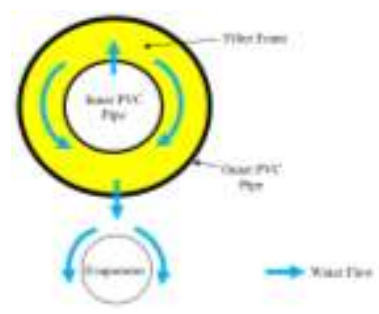

Figure 16. Feeder Tube Cross Section Schematic Diagram

As shown in Figure 16, water flows from the inner pipe with diameter $25 \mathrm{~mm}$ to the outer pipe ( $80 \mathrm{~mm}$ diameter) through the nylon filter foam. The foam is used to filter the unwanted solid substances and to stabilize the flow. Then the flow will come into contact with the top of the evaporator tube and forms a thin water film on the outer surface of the evaporator tube.

\section{v. Discussion and Results}

For desalination purpose, evaporator tube with higher thermal conductivity has better performance in producing condensate. According to Cengel (2006), the aluminium tube has thermal conductivity with $168 \mathrm{~W} / \mathrm{m} . \mathrm{K}$, which was about 68 percent higher than brass-aluminium tube $(100.5 \mathrm{~W} / \mathrm{m} . \mathrm{K})$ used by Noor (1980). Hence the aluminium tube had been selected as evaporator in this study.

\section{A. Surface Roughness Results}

Figure 17 shows the average surface roughness on the rough evaporator tube while Figure 18 shows the average surface roughness on the smooth evaporator tube. Figure 19 shows overall surface roughness profile on rough tube and Figure 20 shows overall surface roughness profile on smooth tube.
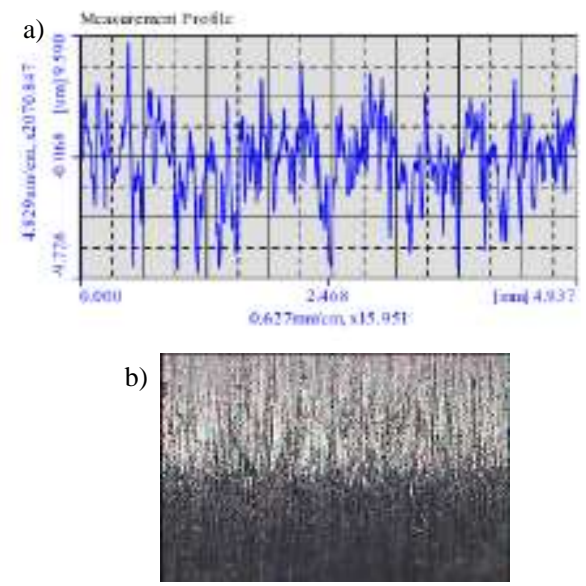

Figure 17. Surface roughness results on point $\mathrm{P} 1$ on rough evaporator tube a) $\operatorname{Ra}(\mu \mathrm{m})=2.085$, b) Surface profile (magnification 15 times)
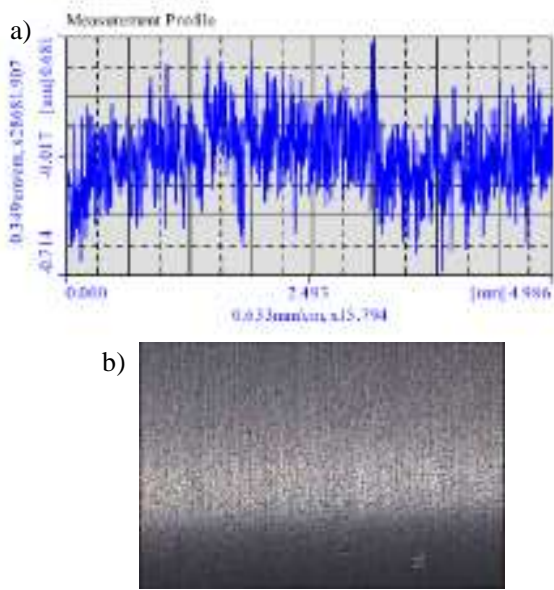

Figure 18. Surface roughness results on point P1 on smooth evaporator tube a) $\mathrm{Ra}(\mu \mathrm{m})=0.138, \mathrm{~b})$ Surface profile (magnification 15 times) 
Proc. of the Intl. Conf. on Advances in Civil, Structural and Mechanical Engineering - ACSM 2015.

Copyright (C) Institute of Research Engineers and Doctors, USA .All rights reserved.

ISBN: 978-1-63248-039-2 doi: 10.15224/ 978-1-63248-039-2-17

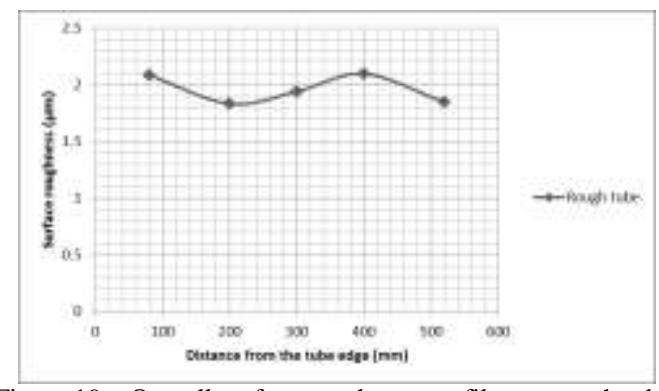

Figure 19. Overall surface roughness profiles on rough tube.

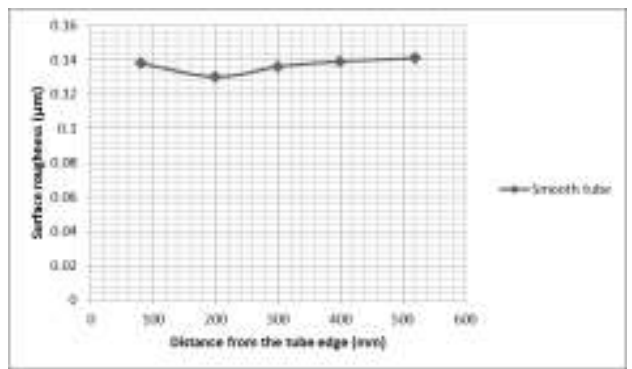

Figure 20. Overall surface roughness profiles on smooth tube.

Based on Figures $19 \& 20$, the average surface roughness of the rough and smooth evaporator tube is $1.961 \mu \mathrm{m} \pm 7 \%$ and $0.137 \mu \mathrm{m} \pm 5 \%$, respectively.

\section{B. Height of the Feeder}

The testing feeder was first designed referring to the study done by Yang and Shen (2008) with height of $11 \mathrm{~mm}$. However due to different diameter of evaporator used in this study, the falling film was not able to cover completely along the evaporator tube. At the liquid load higher than 24 LPM, the feeder water tends to spread out to surrounding after impacted with evaporator tube rather than forming a falling film to cover around evaporator tube. Many dry spots occurred which affected the accuracy of the study. Hence, feeder height was set as $20 \mathrm{~mm}$ which give the minimum value of dry spots with the increment of liquid load from 16 LPM to 32 LPM.

\section{Feeder Film Pattern}

Based on the study done by Roques, Dupont and Thome (2002), the feeder film pattern can be classified into five modes, which are droplet mode, droplet-column mode, column mode, column-sheet mode and sheet mode. Figure 21 shows the film pattern on the rough surface tube and smooth surface tube a feeder load.

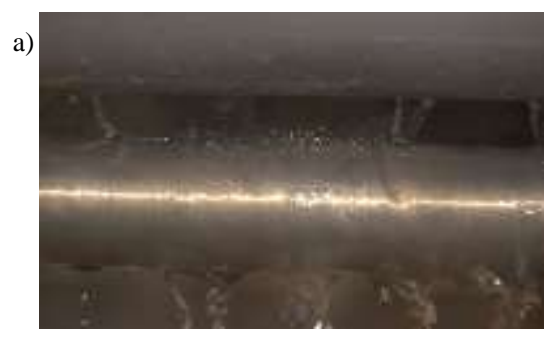

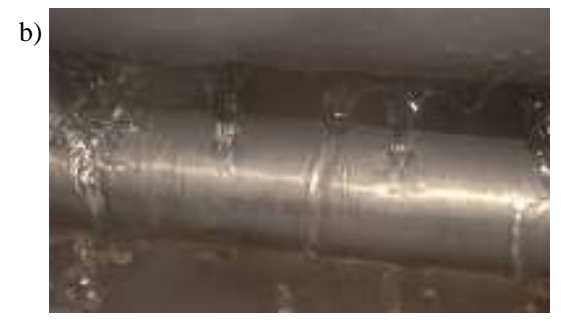

Figure 21. Feeder film with 20 LPM on a) rough surface tube, b) smooth surface tube.

At 20 LPM and below, the pattern changed from sheet mode to column mode. In column mode, dry spots started to occur on the tube. However, the dry spots that occurred on the rough surface tube were relativity lower and. Ming et al. (2011) stated that roughness has an effect on the wetting properties of a surface. Therefore, the rougher the surface, the quantity of the dry spots was lower and the wettability is better.

\section{Condensate steam}

The condensate film inside the tube was assumed to be in equilibrium temperature state. Hence the average condensate bulk temperature was used as condensate temperature in this study in order to simplify data collection. After knowing the conditions, the properties for steam, falling film and condensate were substituted into the modified equation to calculate the theoretical results for each feeder water load. The boundary conditions for the equation are shown in Figure 22.

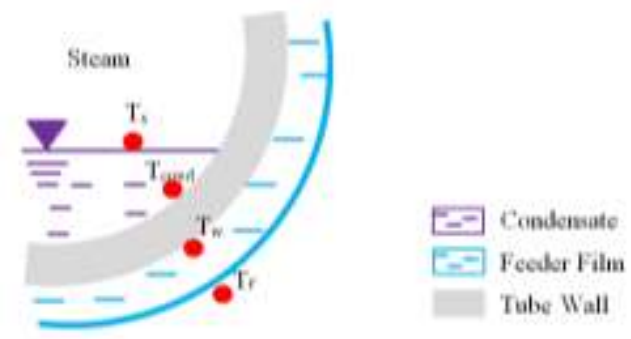

Figure 22. Boundary Condition.

Figure 23 shows the theoretical results for the five different feeder water loads using the modified equation.

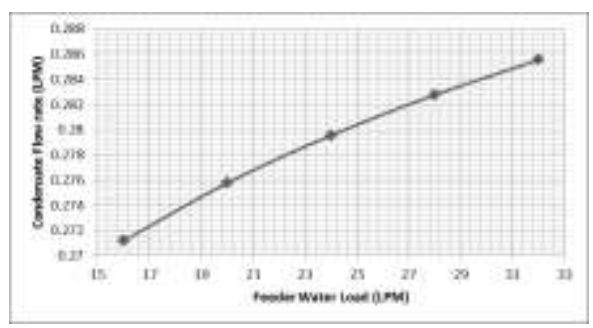

Figure 23. Effects of feeder water load on the condensate flow rate

Results for both the rough and smooth surface are almost similar since both the tubes has similar $\mathrm{T}_{\mathrm{f}}, \mu_{\mathrm{f}}, \rho_{\mathrm{f}}$ and $\mathrm{k}_{\mathrm{f}}$ values. Hence, the results for the smooth surface tube were selected 
and plotted in Figure 24 for further studies. Figure 25 shows the comparison between the previous and the new modified equations.

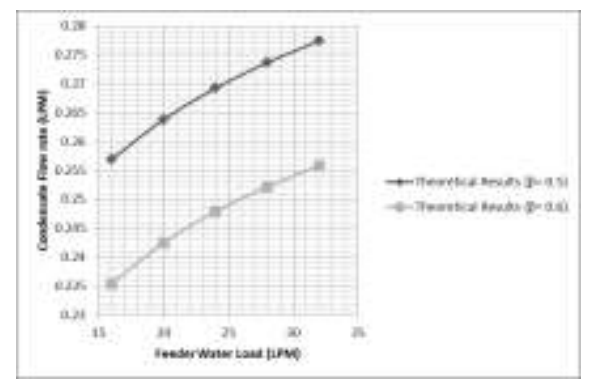

Figure 24. Condensate flow rate against feeder water load based on equation (1).

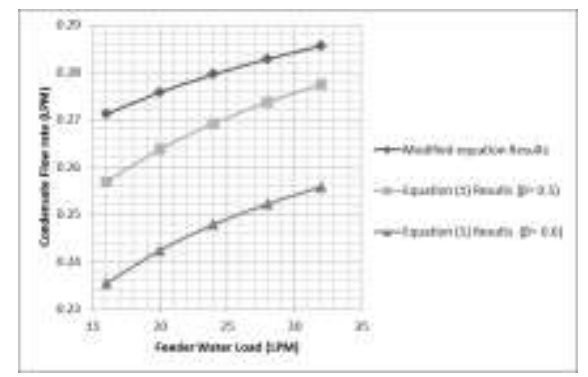

Figure 25. Condensate flow rate against feeder water load for both modified and equation (1).

From Figure 23 and 24, the condensate flow rate is predicted to increase when the feeder loads are increased for both the equations. As shown in Figure 25, the equation (1) with lower $\beta$ value is closer to the modified equation.

\section{E. Experimental Data}

Performance of the evaporator tube was evaluated based on the rate of fresh water volume produced per minute. 14 readings were recorded for each surface roughness on each feeder load and average results were calculated. Figure 26 shows the experimental results under five different feeder water loads on both the rough and smooth outer tube surface.

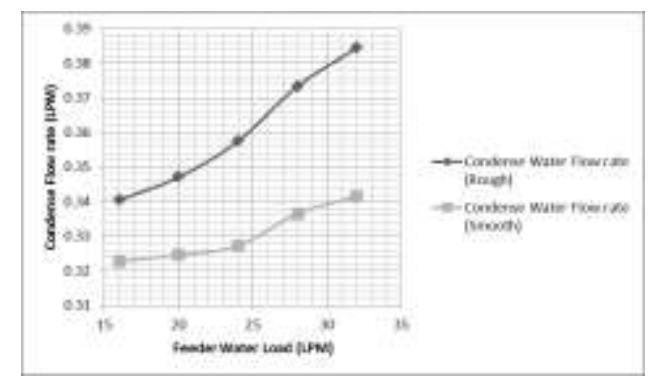

Figure 26. Condensate flow rate against feeder water load on both rough and smooth outer tube surface.
The increments of the feeder water load help to improve the evaporators' performance for both the rough and smooth surface as shown in Figure 26.

\section{vi. Conclusion}

Results show that the performance of the rough outer surface is better compared to the smooth. The evaporator with rough outer surface has about 9 percent more condensate flow rate compared to the one with smooth outer surface. The evaporator with rough outer surface has surface roughness that is 14 times higher, as this condition provides more contact area between the tube and the feeder film. A bigger contact area enables more heat to be transferred from the tube to the film during each time interval. Hence the overall heat transfer of the tube improves and more condensate is produced.

\section{Acknowledgment}

The authors would like to thank UTM-Centre for Low Carbon Transport, Faculty of Mechanical Engineering and Universiti Teknologi Malaysia (UTM) for providing the research facilities. This research work has been supported by UTM Research University Grant (Vot 01G51), FRGS (4F445) and the Ministry of Higher Education Malaysia (MOHE).

\section{Nomenclatures}

\begin{tabular}{lll}
\multicolumn{2}{l}{ Symbols } & \\
$\mathrm{C}_{\mathrm{p}}$ & - & Specific heat at constant pressure \\
$\mathrm{d}$ & - & Diameter \\
$\mathrm{g}$ & - & Gravity \\
$\mathrm{h}$ & - & Heat transfer coefficient \\
$\mathrm{H}$ & - & Latent heat capacity \\
$\mathrm{k}$ & - & Thermal conductivity \\
$\mathrm{L}$ & - & Heat transfer surface length on evaporator \\
$\mathrm{tube}$ & & \\
$\mathrm{T}$ & - & Temperature \\
$\dot{\mathrm{m}}$ & - & Mass flow rate \\
R.H.S & - & Right hand side equation
\end{tabular}

\section{Greek Symbols}

B - - $\quad$ The fraction of summation of inlet and outlet water temperature

$\Gamma \quad$ - $\quad$ Mass flow rate per unit length

$\delta \quad \quad-\quad$ Thickness

$\mu \quad$ - $\quad$ Dynamic viscosity

$\rho \quad$ - Density

\section{References}

[1] Cengel, YA 2006, Heat and Mass Transfer, 3th edn, McGraw-Hill, New York.

[2] Hoyt, CH, James, JM, Adel, FS, Geoffrey, DS, Phillip, CW \& Kent, SK 2008, 'Heat and Mess Transfer', in Perry, RH \& Green, DW (ed), Perry's Chemical Engineers' Handbook, 8th den, McGraw-Hill, New York, pp. 5-11-5-13. 
[3] Leroy, SF \& Sernas, V 1974, 'Evaporation from Thin Water Film on Horizontal Tubes', Ing. Eng. Chem., Process Des. Develop, vol 13: No 3 .

[4] Ming, J, Wu, X, Shen, L \& Gao, F 2011, 'Hydrophilic Treatment and Performance Evaluation of Copper Finned Tube Evaporators', Applied Thermal Engineering, vol.31, pp.2936-2942.

[5] Noor, AM 1980, 'Condensation Inside Tube', Degree thesis, University of Glasgow, Glasgow.

[6] Ribatski, G \& Jacobi, AM 2005, 'Falling Film Evaporation on Horizontal Tubes---a Critical Review', International Journal of Refrigeration, vol. 28, pp. 635-653.

[7] Roques, JF, Dupont, V \& Thome, JR 2002, 'Falling Film Transition on Plain and Enhanced Tubes', Journal of Heat Transfer, vol. 124, pp. 491499.

[8] Wang, J \& Catton, I 2001, 'Enhanced Evaporation Heat Transfer in Triangular Grooves Covered with a Thin Fine Porous Layer', Applied Thermal Engineering, vol. 21, pp.1721-1737.

[9] Wolverine Tube Inc 2006, 'Chapter 8: Condensation inside Tube', in Wolverine Tube Inc (ed.), Engineering Data Book III, W.T.I, Decatur, pp. 8-2.

[10] Xu, L, Ge, M, Wang, S \& Wang, Y 2004a, 'Heat Transfer Film Coefficients of Falling Film Horizontal Tube Evaporation', Desalination, vol. 166, pp. 223-230.

[11] Xu, L, Wang, SY, Wang, S \& Wang, Y 2004b, 'Study on Heat Transfer Film Coefficient inside a Horizontal Tube in Falling Film Evaporators', Desalination, vol. 166, pp.215-222.

[12] Yang, L \& Shen, S 2008, 'Experimental Study of Falling Film Evaporation Heat Transfer outside Horizontal Tubes', Desalination, vol. 220, pp. 654-660.
About Author (s):

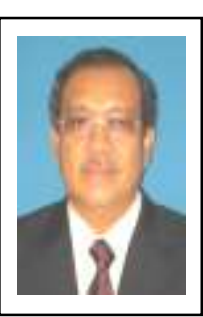

Alias Mohd Noor
Research field : Experience in automotive
turbo-machinery, fluid machinery,
biotechnology (bio-fuels), fluid mechanics,
thermodynamics and heat transfer, gas
dynamics, internal combustion engines and
desalination plants and now professor at
Universiti Teknologi Malaysia

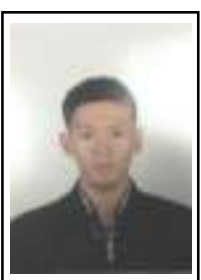

Lim Chih Hoo

Obtain Master Degree in Mechanical

Engineering and currently work as Engineer in private company.

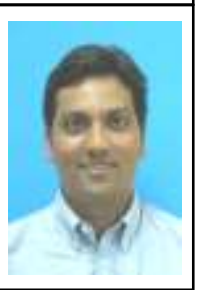

Srithar Rajoo

\begin{tabular}{c} 
Srithar Rajoo \\
Research field : Engine Boosting, downsizing \\
\& waste heat recovery \\
UTM Centre for Low Carbon Transport \\
In cooperation with Imperial College London \\
Universiti Teknologi Malaysia \\
\hline
\end{tabular}

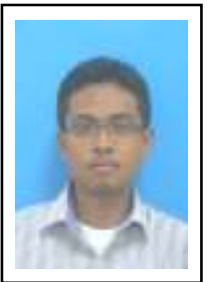

Muhammad Hanafi Md Sah Research Officer

UTM Centre for Low Carbon Transport In cooperation with Imperial College London Universiti Teknologi Malaysia

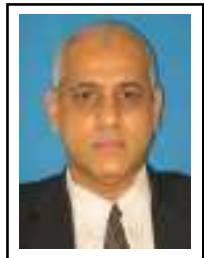

Sheikh Hussain Shaikh Salleh

Research field : Has more than 15 years of working in the field of signal processing and biomechanics sensors and professor of signal processing at Universiti Teknologi Malaysia 